\title{
Las cartas de servicios en la Administración Local
}

\author{
Valentín Merino Estrada \\ Secretario General del Ayuntamiento de Valladolid
}

\begin{abstract}
Sumario: I. LAS CARTAS DE SERVICIOS COMO INSTRUMENTO DE MEJORA EN LAS ADMINISTRACIONES PÚBLICAS. II. LA IMPLANTACIÓN Y DESARROLLO DE CARTAS DE SERVICIOS EN LOS MUNICIPIOS. III. LOS COMPROMISOS COMO ELEMENTO CLAVE DE LAS CARTAS: TIPOLOGÍA Y ALCANCE. IV. GESTIÓN, MEDICIÓN Y REVISIÓN. V. A MODO DE CONCLUSIONES.
\end{abstract}

\section{LAS CARTAS DE SERVICIOS COMO INSTRUMENTO DE MEJORA EN LAS ADMINISTRACIONES PÚBLICAS}

Las Cartas de Servicios son documentos en los que se da a conocer a los ciudadanos los compromisos, en términos de utilidad, fiabilidad, celeridad, etc., que una Administración asume en la prestación de sus servicios.

Las Cartas pretenden ser expresión de un «contrato» entre la Administración y los ciudadanos. Deben pues elaborarse partiendo de las necesidades y expectativas de éstos, que tendrán derecho a reclamar y obtener una compensación o al menos una disculpa formal, en caso de incumplimiento de los compromisos.

Las Cartas de Servicios constituyen un sistema o «modelo» de calidad adecuado a las características de la Administración Pública como gestora de servicios y titular de funciones orientadas al ciudadano.

Como tales surgieron en el Reino Unido, extendiéndose a otros países europeos como Portugal o Italia, donde están muy generalizadas. En España fueron pioneros algunos municipios, comenzando Barcelona en 1996. Para la Administración General del Estado se encuentran reguladas por el Real Decreto 1254/1999, de 14 de julio y el MAP publicó ya por esas fechas una Guía de Cartas de Servicios, útil para implantar este sistema.

Calidad significa satisfacer las demandas y aspiraciones del cliente, con amabilidad, prontitud y eficacia, a costes moderados. Así entendida, más que un objetivo en términos absolutos, se presenta siempre como un proceso de mejora continua: trabajar cada vez mejor al servicio del cliente. 
La Administración Pública es un ente instrumental. No tiene sentido en sí misma, sino sólo en la medida en que satisface las necesidades y resuelve los problemas sociales. Toda la actividad de la Administración debe estar orientada a servir al ciudadano, receptor, usuario o cliente. Aumentar la satisfacción del ciudadano receptor de sus políticas públicas es un principio básico orientador del trabajo en la Administración Pública.

Las Cartas de Servicios son, pues, por su configuración y en esencia, un instrumento de calidad. En primer lugar, porque constituyen un compromiso de servicio y, en segundo lugar, porque expresan una forma de trabajar, orientada al ciudadano, pensada para él y adecuada al cumplimiento del compromiso con la sociedad. Una forma de trabajar que implica el abandono de la tradicional programación «condicional», sustituyéndola por una programación «por objetivos», en función de los destinatarios de la actividad, los ciudadanos.

Se dice que las Cartas de Servicios constituyen además un modelo de calidad de sencilla aplicación y elevado potencial para la mejora continua de los servicios.

La utilidad y potencialidad de las Cartas para la mejora de la Administración Municipal será precisamente el objeto de nuestro análisis.

\section{LA IMPLANTACIÓN Y DESARROLLO DE CARTAS DE SERVICIOS EN LOS MUNICIPIOS}

La Administración Local, sobre todo los Municipios, presenta tres características relevantes, que deben tenerse muy en cuenta a la hora de elegir los instrumentos y diseñar un modelo o sistema de calidad:

- La Administración Municipal es muy compleja en relación con su tamaño, por la diversidad de sus componentes y por el ritmo acelerado de cambio en que se ve inmersa.

- La Administración Municipal está siempre en contacto directo y personal con los ciudadanos.

- La Administración Municipal tiene un liderazgo fuerte y de fácil identificación.

Considerando estas características generales, así como la diversidad de población, estructura y recursos, lo lógico es que cada Municipio diseñe su propio Plan de Calidad, específico, endógeno y mixto, sin atenerse necesariamente y de forma exclusiva a un modelo o sistema. 
En esos planes, las Cartas de Servicios pueden tener un lugar destacado en atención a estas ventajas que presentan:

- Las Cartas de Servicios se confeccionan por el propio Servicio o Unidad gestora que obviamente conoce sus posibilidades y limitaciones. El Servicio asume como suyos los compromisos y no como algo «impuesto» por la organización o núcleo central.

- Las Cartas de Servicios pueden implantarse de forma gradual y progresiva en el conjunto de la Administración Municipal.

Estas ventajas convierten a las Cartas en un instrumento muy útil para organizaciones que destacan por la enorme diversidad entre unos y otros servicios. Otros modelos de normalización o autoevaluación, más globalizadores, menos graduales, se adaptan peor a esta complejidad.

- En las Cartas se fijan compromisos muy concretos y especificos del propio Servicio, en atención a sus receptores o usuarios.

- Al tener que fijarse estándares de calidad concretos y comprometidos, obliga a rediseñar los procesos de trabajo.

- Las Cartas de Servicios son de fácil elaboración, gestión y seguimiento.

Esto permite poner en marcha el sistema sin detraer importantes recursos organizacionales y apoyándose en los propios medios.

- Finalmente, las Cartas de Servicios se complementan muy bien con otros «modelos» y se integran adecuadamente en un Plan de diseño propio.

El Ayuntamiento de Valladolid aprobó a principios del año 2000 el «Plan Marco para la mejora de la calidad en la Administración Municipal» correspondiente al periodo 2000-2003. Este Plan contiene un conjunto integrado de actuaciones a desarrollar, implantar y controlar, en todos los Servicios y Departamentos. En ese momento se disponía ya de la experiencia-piloto desarrollada en la Policía Municipal, con su Carta de Servicios y que el 8 de marzo de ese año fue la primera de Europa en obtener el Certificado de Calidad conforme a la norma UNE-EN-ISO9002.

Este Plan Marco fija como línea de actuación prioritaria y generalizada la implantación de Cartas de Servicios: 
REAL-2002, núm. 290. MERINO ESTRADA, VALENTIN. LAS CARTAS DE SERVICIOS EN LA ADM...

REAL 290 (SEPTIEMBRE-DICIEMBRE, 2002)

\section{«DISEÑO Y APROBACIÓN DE CARTAS DE SERVICIO}

- Conforme a la Normativa, aprobada junto con este Plan, los principales Servicios y Funciones deberán tener Carta aprobada y difundida, antes de diciembre de 2002.

- Antes de presentar para su aprobación una Carta de Servicio, la Unidad responsable deberá desarrollar un Proyecto de Mejora.

El Proyecto de Mejora contendrá aspectos organizativos y de adecuación tecnológica. Estará orientado a garantizar los compromisos de la Carta. Se acompañará un Estudio del nivel de apreciación, receptividad y requerimientos de los ciudadanos, receptores o usuarios.

- La implantación de las Cartas será progresiva, teniendo en cuenta el Diagnóstico (Actuación I) y conforme al plan de prioridades fijado por el Consejo de Dirección Técnico-Administrativa.»

Con el Plan se aprobó la Normativa de Cartas de Servicios, referida a contenidos mínimos, procedimiento de aprobación y publicación, revisión y controles.

El Plan Marco para la Mejora de la Calidad configuró un Sistema de Seguimiento y Control, que integra un Panel de Mando con la medición y seguimiento del cumplimiento de las Cartas de Servicio. La información es mensual y cada semestre se presenta un Informe de la situación al Consejo de Dirección Técnico-Administrativa.

\begin{tabular}{lcc} 
CARTAS DE SERVICIO EN EL AYUNTAMIENTO DE VALLADOLID \\
\hline $\begin{array}{l}\text { DEPARTAMENTO } \\
\text { O SERVICIO }\end{array}$ & $\begin{array}{c}\text { NÚMERO DE } \\
\text { COMPROMISOS }\end{array}$ & $\begin{array}{c}\text { FECHA } \\
\text { IMPLANTACIÓN }\end{array}$ \\
\hline POLICÍA MUNICIPAL & SEIS & $2^{\circ} \mathrm{Sm} .1999$ \\
\hline ATENCIÓN E INFORMACIÓN AL CIUDADANO & DIEZ & $1^{\circ} \mathrm{Sm} .2001$ \\
\hline ATENCIÓN AL CONTRIBUYENTE (G. INGRESOS) & ONCE & $1^{\circ} \mathrm{Sm} .2001$ \\
\hline PARTICIPACIÓN CIUDADANA & DIEZ & $1^{\circ} \mathrm{Sm} .2001$ \\
\hline O.M.I.C. & DIEZ & $1^{\circ} \mathrm{Sm} .2001$ \\
SERVICIO MUNICIPAL DE LIMPIEZA & OCHO & $1^{\circ} \mathrm{Sm} .2001$ \\
\hline SERVICIOS SOCIALES & DIEZ & $2^{\circ} \mathrm{Sm} .2001$ \\
\hline ARCHIVO MUNICIPAL & CINCO & $2^{\circ} \mathrm{Sm} .2001$ \\
CENTRO DE FORMACIÓN DEL PERSONAL & NUEVE & $2^{\circ} \mathrm{Sm} .2001$ \\
\hline INSTALACIONES DEPORTIVAS & DIEZ & $1^{\circ} \mathrm{Sm} .2002$ \\
\hline MEDIO AMBIENTE & SIETE & $2^{\circ} \mathrm{Sm} .2002$ \\
\hline INSTITUTO MUNICIPAL DE EMPLEO & SIETE & $2^{\circ} \mathrm{Sm} .2002$ \\
\hline PARQUES Y JARDINES & OCHO & $2^{\circ} \mathrm{Sm} .2002$ \\
\hline CONTROL DE LA LEGALIDAD VIAL & DIEZ & $2^{\circ} \mathrm{Sm} .2002$ \\
\hline LICENCIAS URBANÍSTICAS & NUEVE & $1^{\circ} \mathrm{Sm} .2003$ \\
\hline
\end{tabular}


En el momento actual están aprobadas, difundidas y controladas 15 Cartas de Servicios, con un total de 130 compromisos. Afectan directamente al $80 \%$ de los empleados municipales.

Del seguimiento efectuado, de los estudios de revisión de las Cartas en Valladolid y del análisis del conjunto de Cartas publicadas por Municipios a los que hemos tenido acceso, podemos apuntar que la utilidad, en términos de mejora real de la calidad, depende de dos factores:

- El nivel de concreción de los compromisos.

- El alcance de la medición que se efectúe, sobre datos tanto de gestión como de percepción.

\section{LOS COMPROMISOS COMO ELEMENTO CLAVE DE LAS CARTAS: TIPOLOGÍA Y ALCANCE}

En el contenido de las Cartas de Servicios distinguimos dos grandes apartados: Información y Compromisos.

Como elementos de información tenemos:

- Los datos de identificación del órgano prestador del Servicio, complementados con: las direcciones postales, telefónicas y telemáticas; los medios de acceso y transporte y la identificación del directivo o responsable de la Unidad.

- La Relación de Servicios prestados. Derechos de los usuarios. Formas de colaboración y participación. Normativa reguladora.

- Formas de presentación de quejas y sugerencias. Mención al Libro de Quejas y Sugerencias. Otras formas de presentación, con indicación de sus efectos y plazos de contestación.

Sólo un ciudadano informado puede hacer valer sus derechos e impulsar a la Administración a trabajar con calidad. La información está siempre en la base de una correcta interacción Administración-Ciudadano. Por ello el contenido informativo de las Cartas de Servicios es importante, especialmente el que se refiere a las formas de presentación de quejas y sugerencias.

Pero el núcleo fundamental de las Cartas está constituido por la declaración de compromisos que la organización asume en la prestación del servicio. 
La clave está en los compromisos porque son el elemento que aporta valor añadido en relación con lo establecido por las normas reguladoras del servicio y porque al fijar metas concretas, públicas y comprometidas, facilitan la mejora continua.

La Guía para la implantación de Cartas de Servicios, elaborada por el M.A.P., dice: «Con carácter general, los compromisos de calidad deben revestir la forma de estándares numéricos (plazos, tiempo de espera...) y ser susceptibles de verificación por el usuario».

Los compromisos deben ser concretos y cuantificados. Además, para favorecer el proceso de mejora continua, en interacción con los ciudadanos, deben resultar perceptibles y en alguna medida controlables por ellos.

Sin embargo, en el conjunto de Cartas estudiadas observamos una gran variedad de compromisos. Sintetizando, podemos agruparlos en esta sencilla tipología, en función de los criterios básicos expuestos:

\section{- Compromisos no cuantificados}

Se trata de compromisos generales. En ocasiones son meras declaraciones de voluntad, que reiteran lo dicho por las normas. En otras tiene mayor concreción, pero no llevan asociado ningún indicador, ni fijan un estándar.

Sobre el cumplimiento de este tipo de compromisos se puede hacer valoración, incluso documentar las percepciones valorativas de los ciudadanos (en general se puede hacer aunque no exista compromiso explícito). Pero no se puede efectuar medición de ningún tipo.

\section{- Compromisos cuantificados, no verificables}

Son compromisos concretos, en los que se fija un determinado estándar de cumplimiento y medibles. Sin embargo, debido a su carácter interno no son verificables por el receptor, usuario o cliente. Se trata por lo general de compromisos asociados al alcance de determinados niveles de gestión. Resultan muy interesantes como objetivos operativos de gestión pero su potencialidad para la mejora continua es limitada pues el cliente o ciudadano no podrá verificar su cumplimiento.

\section{- Compromisos cuantificados y verificables}

Son compromisos concretos y cuantificados, controlables de alguna manera por el usuario o receptor, que puede verificar el nivel de cumplimiento. 
Son los compromisos que tienen más utilidad y mayor potencialidad para la mejora continua por dos razones:

- Porque pueden ser objeto de medición en base a datos de gestión y de percepción.

- Porque el ciudadano puede exigir de forma clara y concreta su cumplimiento.

Una variante de este tipo son los compromisos que asocian de forma explícita una compensación a favor de los afectados por los incumplimientos. Podemos considerarlo el nivel más alto de compromisos.

Los distintos tipos no pueden entenderse como compartimentos estancos. En realidad, desde la mera declaración de intenciones al compromiso más claro y controlable existe una escala gradual y continua.

Así, entre los compromisos cuantificados y no verificables, algunos pueden ser «controlados» de forma indirecta por el ciudadano y sus percepciones ser objeto de medición asociada. Por ejemplo, en la Carta del Servicio de Limpieza encontramos el siguiente compromiso: «320.000 horas de trabajo de limpieza viaria al año». Es un objetivo interno de gestión. Pero podemos asociar una medición perceptiva a dos valoraciones ciudadanas: presencia de trabajadores detectada y limpieza de las calles.

Por otro lado, entre los compromisos del tercer tipo, es muy frecuente encontrar esta formulación: «Resolver.... en un plazo máximo de...., el $80 \%$ de los casos». Interesante para el control de gestión. Pero desde el punto de vista del ciudadano, la verificación deja mucho que desear. Al que no se le resuelva en el plazo fijado, deberá pensar que su mala suerte le colocó entre el $20 \%$ que tendrán que aguantarse.

Por ello, más que establecer niveles en función del porcentaje de compromisos de un tipo u otro en las Cartas, lo importante es poner el acento en la génesis de los compromisos. Éstos deben surgir en el proceso de diseño del servicio basado en las expectativas del usuario, de una selección adecuada de características relevantes, a las que se asocien estándares de calidad, indicadores y finalmente compromisos.

Los usuarios, e incluso los ciudadanos en general, tienen unas expectativas sobre los servicios que la Administración les presta. Además de manifestar una opinión global sobre el Servicio, son capaces de juzgar sus distintos «elementos» o atributos, aunque a veces les sea difícil explicitarlo adecuadamente. 
Los atributos de calidad son los «componentes» del Servicio que el usuario o receptor valora de forma especial y puede percibir con claridad por separado. No todos los componentes de un servicio son valorados igual por los usuarios, ni por lo tanto tendrán igual importancia.

Para diseñar adecuadamente un servicio es necesario identificar los atributos de calidad desde la óptica del usuario, investigando además el peso que a cada uno le asigna.

Para ello es preciso preguntar a los usuarios por medio de Encuestas.

Las encuestas a los usuarios sobre sus expectativas en un determinado Servicio se pueden confeccionar en base a preguntas sobre los atributos generales que establece el Modelo SERVQVAL, para conocer la importancia relativa que conceden los usuarios a cada criterio, en el Servicio de que se trate. El Modelo SERVQVAL establece, en términos generales, la importancia que los usuarios conceden a los cinco criterios-dimensiones de la calidad. Si se usan como elemento sustitutivo de las encuestas conviene tener en cuenta que en los Servicios de la Administración Municipal, el usuario pondera más el criterio «Capacidad de Respuesta» en términos de rapidez-puntualidad, por encima de la «Fiabilidad».

Una vez que conozcamos los atributos de calidad, tal y como los formula el usuario y la importancia relativa que concede a cada uno de ellos, deberemos hacerlos operativos traduciéndolos a aspectos concretos que definirán las características del Servicio.

Las características del Servicio son aquellos aspectos que el gestor selecciona y que constituyen el producto o servicio diseñado. Cada característica debe estar destinada a satisfacer uno o varios atributos de calidad.

Los requisitos de un Servicio deben estar claramente definidos en términos de características que sean observables y sometidas a evaluación del usuario. 


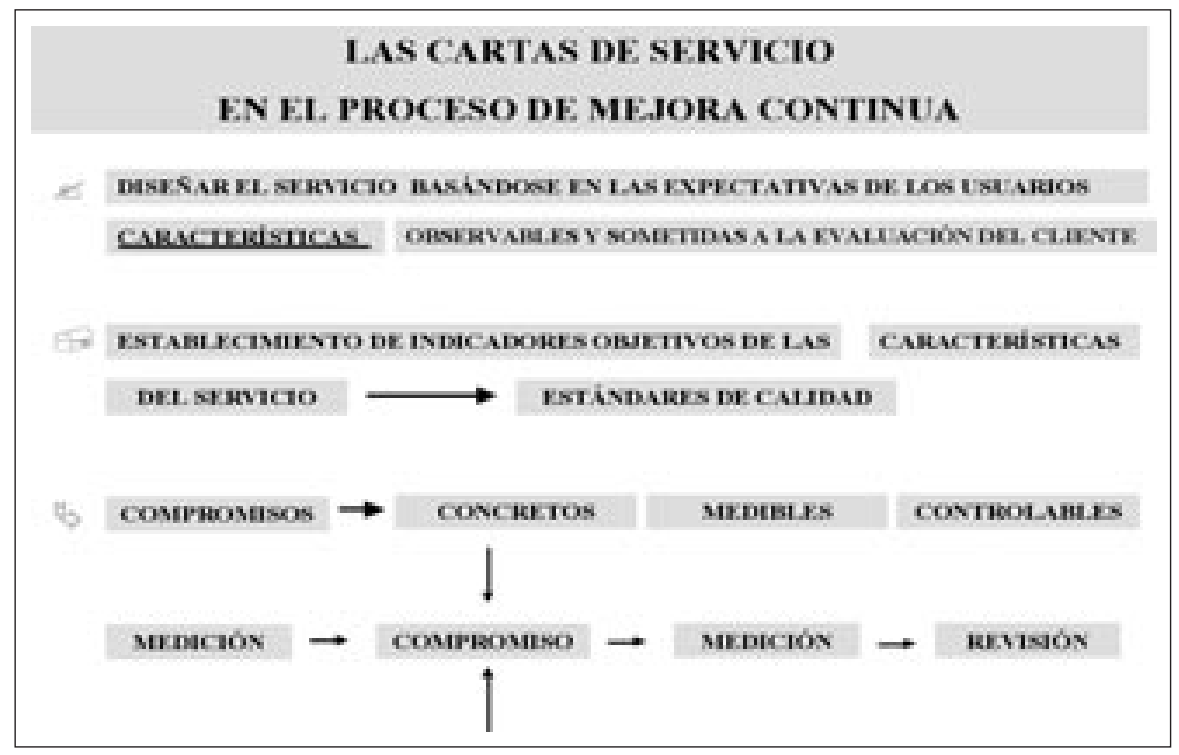

El proceso de mejora continua requiere, ante todo, medir. Para poder medir es necesario establecer las variables a medir y los valores que se esperan alcanzar en dichas variables.

Para poder llevar a cabo el proceso de medición, cada característica del Servicio deberá traer asociado uno o varios «indicadores objetivos» y para cada uno de ellos se fijará el nivel estándar que nos proponemos alcanzar.

Un indicador es una magnitud asociada a una característica que permite, a través de su medición en periodos sucesivos y por comparación con el estándar establecido, evaluar periódicamente dicha característica y verificar el cumplimiento de los objetivos establecidos para el servicio. Esta medición nos permitirá pues implantar una estrategia de mejora.

Definir las características del Servicio, seleccionar indicadores asociados y fijar estándares son elementos claves para conformar una Carta de Servicios.

Llegados a este punto, sólo tendremos que seleccionar aquellas características más «visibles» y verificables por el ciudadano o el usuario y expresarlas como Compromisos, con el estándar fijado. 


\section{GESTIÓN, MEDICIÓN Y REVISIÓN}

Una vez implantada y difundida la Carta de Servicios, es preciso realizar un correcto seguimiento. Para ello necesitaremos un buen sistema de medición, que nos aporte la información necesaria para adoptar las decisiones de revisar los compromisos, de corregir y con ello mejorar.

La determinación de los compromisos en el proceso de diseño del Servicio antes expuesta nos sitúa en magnificas posiciones para el correcto seguimiento de la Carta, pues tendremos la base del sistema de medición. Si éste se desarrolla con una revisión constante y responsable, la utilidad de la Carta para la mejora continua será indiscutible.

En el Servicio Municipal de Limpieza de Valladolid, al implantarse la Carta de Servicios, se partía de un buen nivel de gestión, con procesos de trabajo bien definidos y resultados más que aceptables.

Para fijar los compromisos, se analizaron las expectativas de los usuarios y se intentó detectar las características más importantes para ellos. A esas características se asociaron indicadores objetivos y se definió en cada caso un estándar de calidad, generalmente en tiempo de respuesta.

Los compromisos establecidos son objeto de medición, tanto en gestión interna como en percepción ciudadana. En cuatro de los ocho compromisos establecidos, el 10\% de los usuarios identificados son encuestados.

Los resultados de las mediciones permiten revisar los compromisos, mejorar la gestión y apuntalar la calidad de atención al usuario, que es lo más importante. 


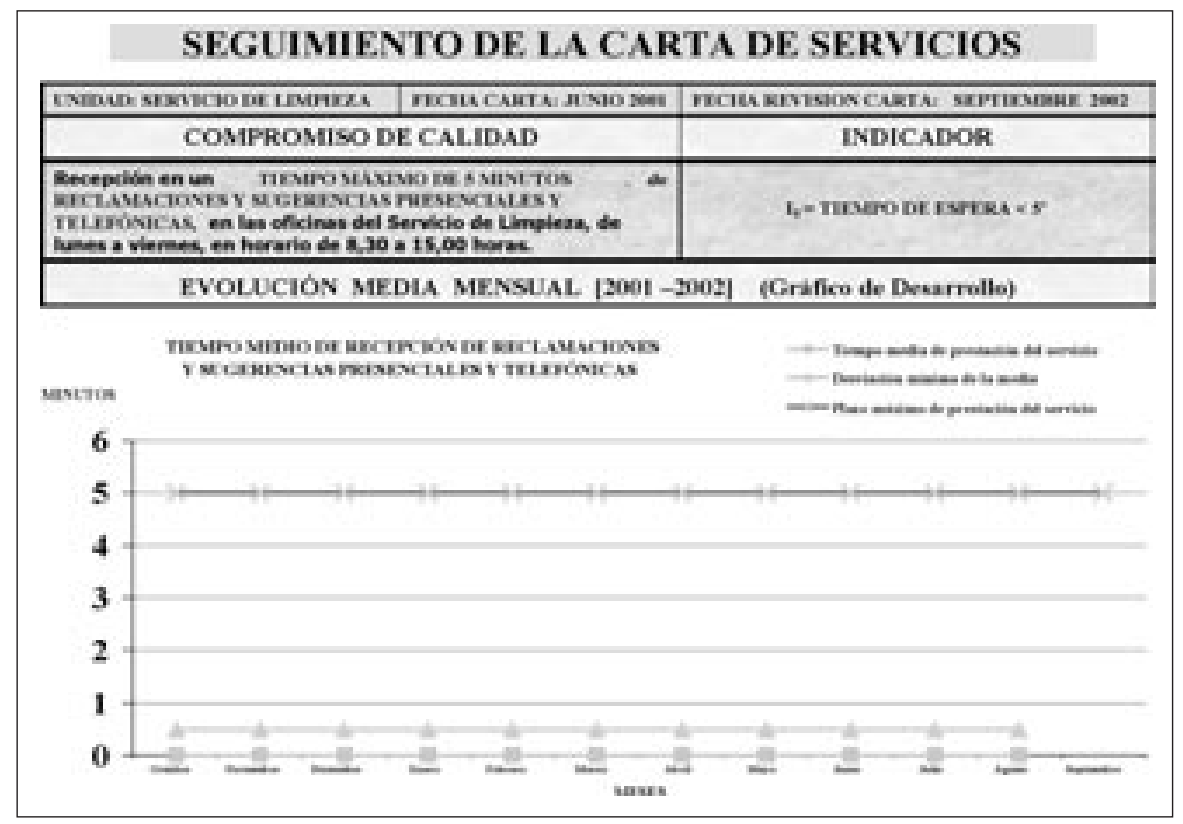

En este compromiso vemos que la atención presencial y telefónica se realiza de inmediato, sin tiempos de espera. No existen desviaciones a la media que destacar. El estándar fijado debe modificarse, reduciéndose.

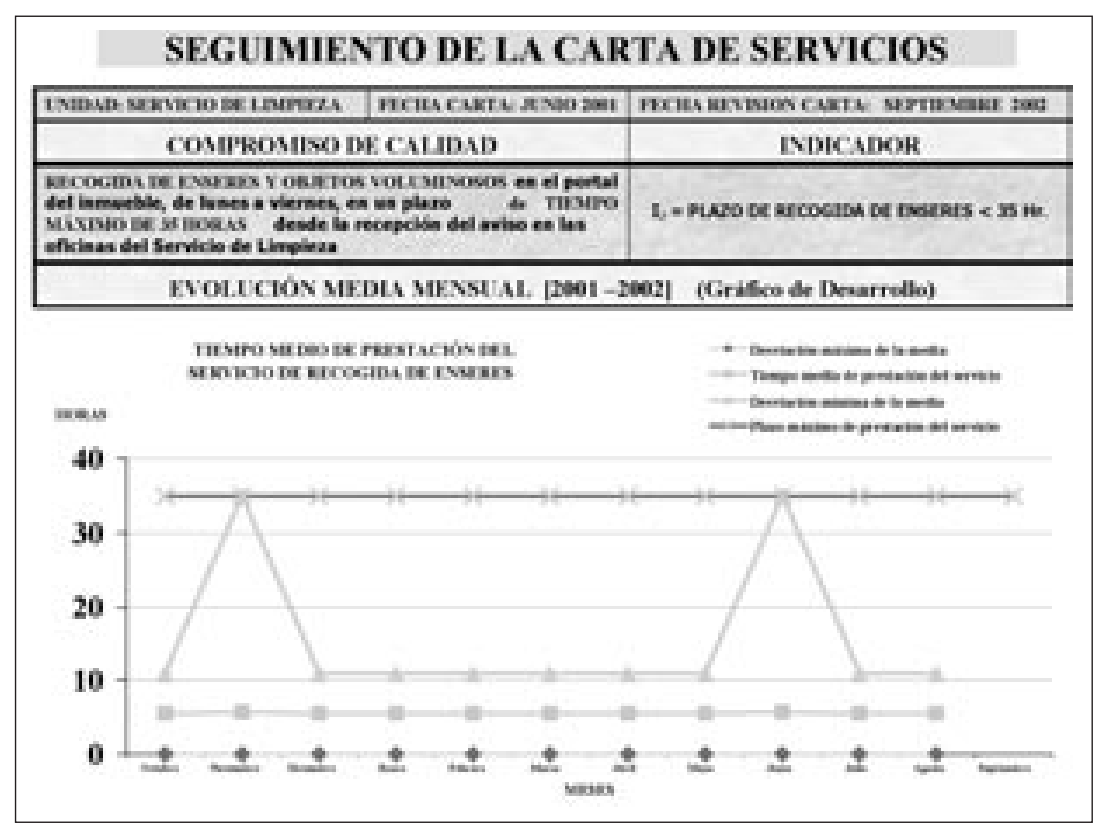


En este compromiso, los tiempos medios de respuesta están muy por debajo del estándar fijado, pero con desviaciones concretas que suponen un riesgo, pues nos sitúan al límite. Estas desviaciones están localizadas en periodos de tiempo muy concretos. Parece lógico revisar el estándar comprometido, a la baja, pero tras adoptarse medidas de refuerzo en esas fechas «peligrosas».

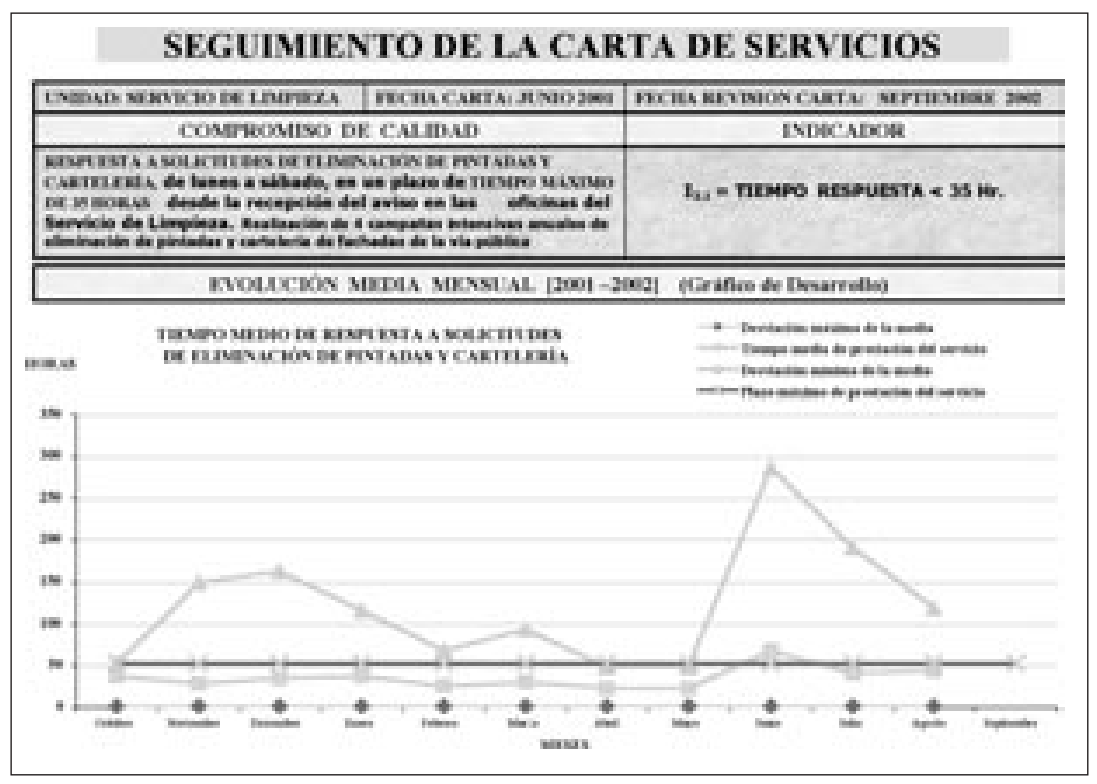

Por el contrario, en este compromiso, los tiempos medios de respuesta están muy ajustados. Además, las desviaciones a la media son notables y casi constantes en el tiempo. La mejora exige adoptar medidas de refuerzo, sin descontarse la revisión del estándar al alza.

Cuando un año después de implantarse la Carta de Servicios el S.M.L. inició los trabajos de manualización y demás para obtener Certificación conforme a Normas ISO, el terreno estaba muy abonado. Actualmente, con la Certificación conseguida, la gestión con calidad es mejor, pero sin duda el gran salto se dio con la Carta de Servicios.

La utilidad de las Cartas, así enfocadas, puede ser muy notable. 


\section{A MODO DE CONCLUSIONES}

Las Cartas de Servicios pueden ser un instrumento útil en el proceso de mejora continua, con la ventaja de ser sencillas como sistema. Se adaptan muy bien a las características de la Administración Municipal. Por ello, constituyen un buen punto de arranque para gestionar con calidad.

Las claves están en el tipo de compromisos y en el sistema de medición.

El Servicio debe diseñarse escuchando a los ciudadanos y especialmente a receptores, usuarios o clientes. Los compromisos deben referirse a características del Servicio, especialmente visibles y verificables por los ciudadanos, a las que se asocian indicadores y estándares de calidad.

A partir de esta configuración de los compromisos, se deberá disponer de un sistema de medición y revisión que facilite la toma de decisiones.

En estas condiciones la potencialidad de las Cartas para la mejora continua es indudable. 